of their daily living and their physical health-related quality of life. Greater tendency to catastrophize in the face of pain and higher depression levels were associated with more severe pain suggesting that psychological interventions aiming at reducing these factors could be beneficial for some patients with TMO

References:

[1] Bijsterbosch J, Visser W, Kroon HM, Stamm T, Meulenbelt I, Huizinga TW, Kloppenburg M. Thumb base involvement in symptomatic hand osteoarthritis is associated with more pain and functional disability. Annals of the rheumatic diseases. 2010;69:585-587.

[2] Gehrmann SV, Tang J, Li ZM, Goitz RJ, Windolf J, Kaufmann RA. Motion deficit of the thumb in CMC joint arthritis. Journal of hand surgery. 2010;35:1449-1453.

[3] Botha-Scheepers S, Riyazi N, Watt I, Rosendaal FR, Slagboom E, Bellamy $\mathrm{N}$, Breedveld FC, Kloppenburg M. Progression of hand osteoarthritis over 2 years: a clinical and radiological follow-up study. Annals of the rheumatic diseases. 2009;68:1260-1264.

[4] Hwang RW, Ring D. Pain and disability related to osteoarthrosis of the trapeziometacarpal joint. J Hand Microsurg. 2011;3:63-65.

Acknowledgments: This study was supported by a discretionary fund of the Centre de recherche du CHUM (CRCHUM) to Choinière and from the Multidisciplinary Council of the CHUM. Hamasaki was supported by a Doctoral training award of the Fonds de recherche du Québec-Santé, a doctoral scholarship from the CHUM Foundation to Harris (Hand Surgery Branch) and from Choinière's internal funds of the CRCHUM.

Disclosure of Interests: None declared

DOI: 10.1136/annrheumdis-2020-eular.536

\section{FRI0609-HPR NUTRIENTS INTAKE CONDITION RELATES TO MAINTENANCE LOW DISEASE ACTIVITY IN PATIENTS WITH RHEUMATOID ARTHRITIS DURING 6 YEARS: TOMORROW STUDY}

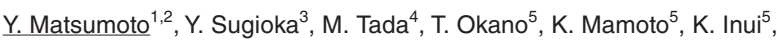
D. $\mathrm{Habu}^{2}$, T. Koike ${ }^{1,3} .{ }^{1}$ Search Institute for Bone and Arthritis Disease (SINBAD), Shirahama Foundation for Health and Welfare, Shirahama, Japan; ${ }^{2}$ Osaka City University Graduate School of Human Life Science, Department of Medical Nutrition, Osaka, Japan; ${ }^{3}$ Osaka City University Medical School, Center for Senile Degenerative Disorders (CSDD), Osaka, Japan; ${ }^{4}$ Osaka City General Hospital, Department of Orthopaedic Surgery, Osaka, Japan; ${ }^{5}$ Osaka City University Medical School, Department of Orthopaedic Surgery, Osaka, Japan

Background: We have previously reported that nutritional intake status might relate to disease activity (1). Nutritional survey on prospective cohort study in rheumatoid arthritis (RA) patients and information about relationship between nutritional intake status and disease activity was very limited.

Objectives: This study aimed to obtain data from a cohort study for new nutritional therapy in RA patients.

Methods: We used TOMORROW cohort study data which conducted from years of 2010 to 2020. Two hundred and eight RA patients, and 205 non-RA sex and age matched controls were investigated, and we analyzed data from 2011 to 2017. Nutritional intake status was compared between who maintain lower disease activity during 2011 to 2017 (LDA group) and being higher disease activity even once in 2011 to 2017 (non-LDA group). Disease activity was evaluated by DAS28-ESR in every year and nutritional intake status was surveyed by brief self-administered diet history questionnaire (BDHQ) in 2011 and 2017.

Results: In RA patients, the change value from 2011 to 2017 of iron (odds ratio; 2.37), thiamin (OR; 2.96) and folic acid (OR; 3.16) intake which adjusted by energy intake, age, rheumatoid factor and medication status were extracted as independent factors for maintain LDA by multivariate logistic regression. These nutrients intake in RA patients was significantly lower than control both in 2011 and 2017. In RA patients, iron and folic acid intake in LDA group was significantly lower than non-LDA group in 2011. Folic acid intake was increased in LDA group and decreased in non-LDA group over time, and these nutrients showed significant differences in change value between LDA group and non-LDA group $(p<0.05)$.

Conclusion: The overtime change value in iron, thiamin and folic acid related to maintain six years low disease activity in RA patients.

References:

[1] Matsumoto Y, Sugioka Y, Tada M, Okano T, Mamoto K, Inui K, et al. Monounsaturated fatty acids might be key factors in the Mediterranean diet that suppress rheumatoid arthritis disease activity: The TOMORROW study. Clinical Nutrition 37:675-680, 2018
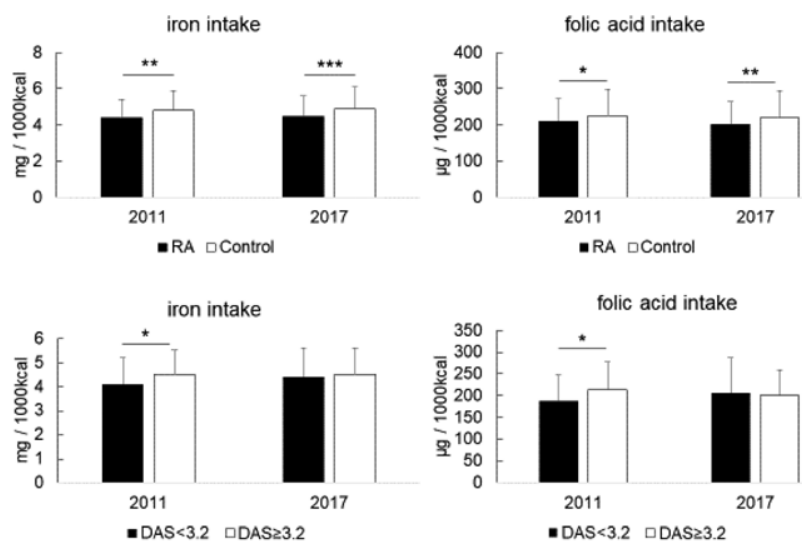

Disclosure of Interests: Yoshinari Matsumoto Grant/research support from: Yamada Research Grant (grant No.249), Yuko Sugioka: None declared, Masahiro Tada: None declared, Tadashi Okano Grant/research support from: AbbVie, Eisai, Mitsubishi Tanabe Pharma Corporation and Nipponkayaku, Speakers bureau: AbbVie, Asahikasei, Astellas Pharma Inc, Ayumi Pharmaceutical, Bristol-Myers Squibb, Chugai Pharmaceutical, Daiich Sankyo, Eisai, Janssen, Lilly, Mitsubishi Tanabe Pharma Corporation, Novartis Pharma, Ono Pharmaceutical, Pfizer, Sanofi, Takeda Pharmaceutical, Teijin Pharma and UCB, Kenji Mamoto: None declared, Kentaro Inui Grant/research support from: Janssen Pharmaceutical K.K., Astellas Pharma Inc. Sanofi K.K., Abbvie GK, Takeda Pharmaceutical Co. Ltd., QOL RD Co. Ltd., Mitsubishi Tanabe Pharma, Ono Pharmaceutical Co. Ltd., Eisai Co.,Ltd.,, Speakers bureau: Daiichi Sankyo Co. Ltd., Mitsubishi Tanabe Pharma, Janssen Pharmaceutical K.K. Astellas Pharma Inc., Takeda Pharmaceutical Co. Ltd., Ono Pharmaceutical Co. Ltd., Abbvie GK, Pfizer Inc., Eisai Co.,Ltd., Chugai Pharmaceutical Co., Ltd., Daik Habu: None declared, Tatsuya Koike Grant/research support from: AbbVie, Astellas Pharma Inc, Bristol-Myers Squibb, Chugai Pharmaceutical, Eisai, Janssen, Lilly, Mitsubishi Tanabe Pharma Corporation, MSD, Ono Pharmaceutical, Pfizer, Roche, Takeda Pharmaceutical, Teijin Pharma, and UCB, Speakers bureau: AbbVie, Astellas Pharma Inc, Bristol-Myers Squibb, Chugai Pharmaceutical, Eisai, Janssen, Lilly, Mitsubishi Tanabe Pharma Corporation, MSD, Ono Pharmaceutical, Pfizer, Roche Takeda Pharmaceutical, Teijin Pharma, and UCB

DOI: 10.1136/annrheumdis-2020-eular.4058

\section{FRI0610-HPR B-ADRENORECEPTOR BLOCKING DRUGS ASSOCIATE WITH LOWER RISK OF KNEE OSTEOARTHRITIS AND KNEE PAIN CONSULTATIONS IN PRIMARY CARE: A PROPENSITY SCORE MATCHED COHORT STUDY USING THE CLINICAL PRACTICE RESEARCH DATALINK.}

G. Nakafero ${ }^{1}$, M. Grainge ${ }^{2}$, A. Valdes ${ }^{1,3}$, N. Townsend ${ }^{4}$, C. Mallen ${ }^{5}$, W. Zhang ${ }^{1}$, M. Doherty ${ }^{1}$, M. Mamas ${ }^{6}$, A. Abhishek ${ }^{1,3}$. ${ }^{1}$ University of Nottingham, Academic Rheumatology, School of Medicine, Nottingham, United Kingdom; ${ }^{2}$ University of Nottingham, Epidemiology and Public Health, School of Medicine, Nottingham, United Kingdom; ${ }^{3}$ University of Nottingham, Nottingham NIHR-BRC,

Nottingham, United Kingdom; ${ }^{4}$ University of Bath, Public Health Epidemiology, Department for Health, Bath, United Kingdom; ${ }^{5}$ Keele University, School of Primary, Community and Social Care, Keele, United Kingdom; ${ }^{6}$ Keele University, Cardiology, Keele, United Kingdom

Background: The pharmacologic management of OA is centred around optimising pain control but first-line analgesics only have modest efficacy ${ }^{1}$. Findings from several studies suggest that $\beta$-adrenoreceptor blocking drugs ( $\beta$-blockers) have anti-nociceptive effects ${ }^{2}{ }^{3}$. However, evidence for the benefits of $\beta$-blockers in the context of OA pain is scarce. We recently demonstrated, for the first time, an association between beta-blockers and lower pain severity, and less opioid analgesic use in a secondary analysis of data for community dwelling adults with large-joint lower $\mathrm{OA}^{4}$. This association, however, was not confirmed in a hospital-based study ${ }^{5}$. Objectives: We examined [1] the association between $\beta$-blocker prescription and first primary care consultation for knee OA, hip OA, knee pain, and hip pain and [2] the classes of $\beta$-blocker drugs that reduce the risk of these outcomes.

Methods: This was a cohort study using data from the UK Clinical Practice Research Datalink. Participants aged $\geq 40$ years, in receipt of $\geq 2 \beta$-blocker prescriptions within 60 days were matched by age, sex, and propensity score (PS) for $\beta$-blocker prescription to one control using greedy nearest neighbour matching. Participants with chronic painful conditions, contra-indications to $\beta$-blockers, 